\title{
KINETICS OF CALCITE DISSOLUTION
}

\section{SEPTEMBER 1973 - NUMBER 21}

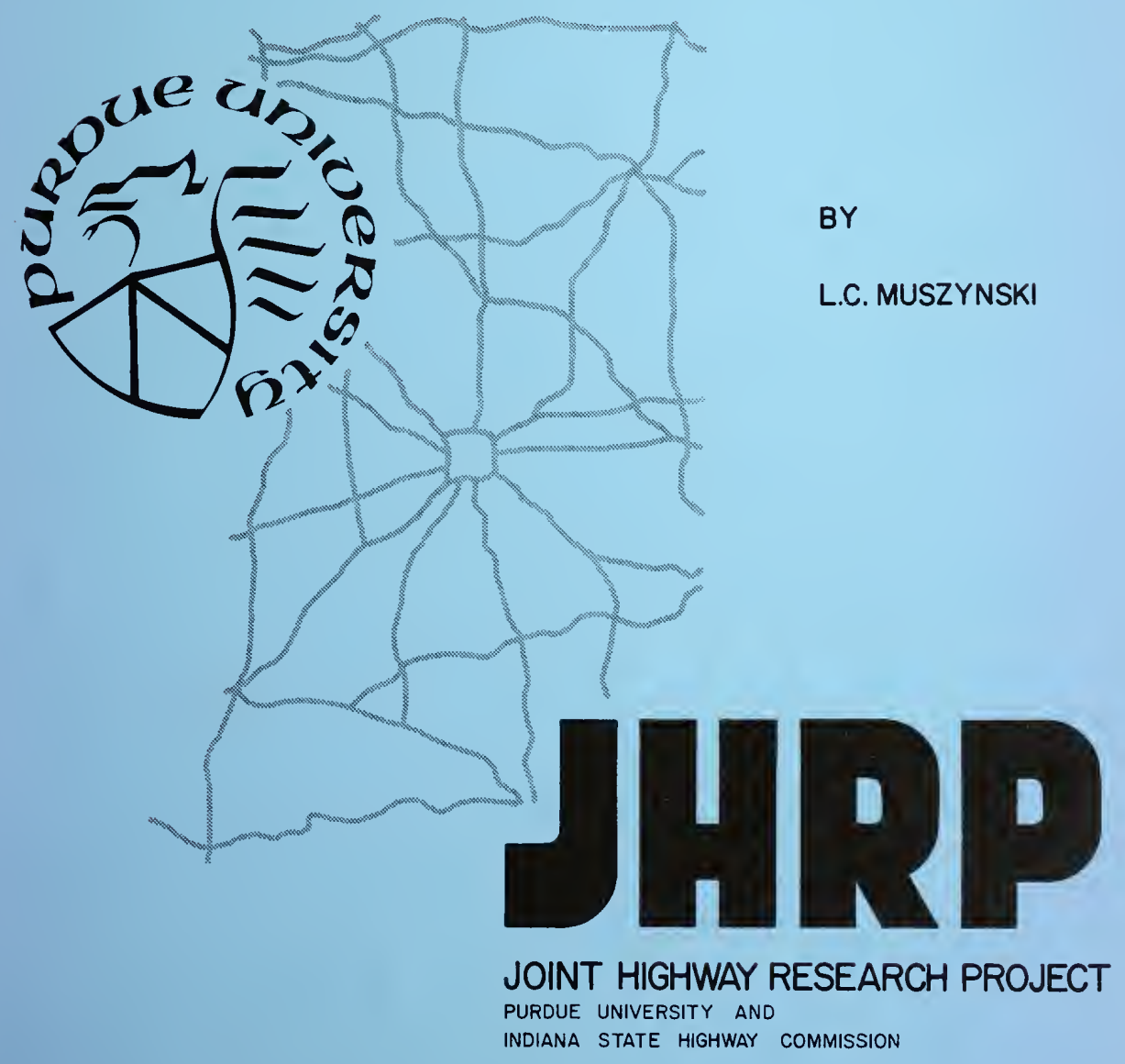





\section{KINETICS OF CALCITE DISSOLUTION}

T0: J. F. MCLaughlin, Director

Joint Highway Research Project

FROM: H. L. Michael, Associate Director Joint Highway Research Project
September 14, 1973

Project: $\quad$ C $-36-47 M$

File: $\quad 4-6-13$

The attached Final Report titled "Kinetics of Calcite Dissolution" is on the approved J.H.R.P. Research Study of the same title. It has been authored by Mr. Larry C. Muszynski, Graduate Assistant in Research on our staff under the direction of Professor W. L. Dolch.

The objective of the Study was to investigate the influence of retarders, both proprietary substances and pure chemicals, on the rate of dissolution of calcite by dilute $\mathrm{HCl}$. Findings included that admixtures decreased the reaction velocities and the rate constants and that activation energies were generaliy increased.

The Report is submitted to the Board for acceptance as fulfillment of the objectives of the Study.

Respectfully submitted,

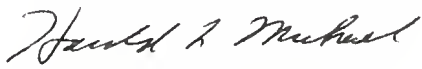

Harold L. Michael

Associate Director

HLM:ms
CC: W. L. Dolch
R. H. Harrell
R. L. Eskew
M. L. Hayes
G. D. Gibson
C. W. Lovell
W. H. Goetz
G. W. Marks
M. J. Gutzwiller
R. D. Miles
G. K. Hallock
G. T. Satterly
C. F. Scholer
M. B. Scott
J. A. Spooner
N. W. Steinkamp
H. R. J. Walsh
E. J. Yoder 


\title{
Final Report \\ KINETICS OF CALCITE DISSOLUTION
}

\author{
by \\ Larry C. Muszynski \\ Joint Highway Research Project \\ Project No.: C-36-47M \\ File No.: $4-6-13$

\begin{abstract}
Conducted by
Joint Highway Research Project Engineering Experiment Station

Purdue University

In Cooperation with

Indiana State Highway Commission
\end{abstract}

\author{
Purdue University \\ West Lafayette, Indiana \\ September 14, 1973
}




\section{ACKNOWLEDGEIVENTS}

The Author wishes to express his appreciation to his major professor, Dr. W. I. Dolch, for his active participation, suidance, and understanding during the course of this work. The valuable suggestions and technical advice of Dr. S. Diamond are gratefully acknowledged.

This research was sponsored by the Indiana Highway Dopartment and administered by Joint Highway Research Project of Purdue University. This support is graterully acknowledgred. 
TABLE OF CONTENTS

Page

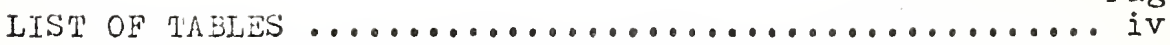

LIST OF FIGURES....................... v

ABSTRACT $\ldots \ldots \ldots \ldots \ldots \ldots \ldots \ldots \ldots \ldots \ldots \ldots \ldots \ldots \ldots \ldots \ldots \ldots \ldots \ldots$

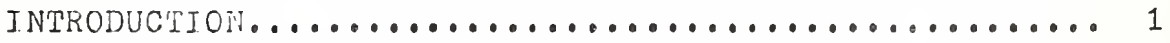

LITERATURE REVIEW ............................. 4

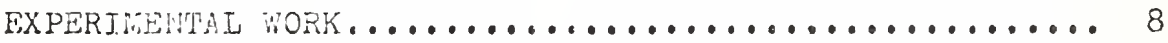

Materials ........................... 8

Apparatus and Procedure $\ldots \ldots \ldots \ldots \ldots \ldots \ldots \ldots$

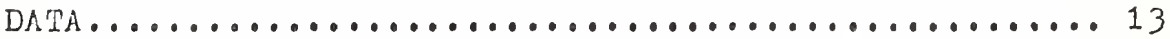

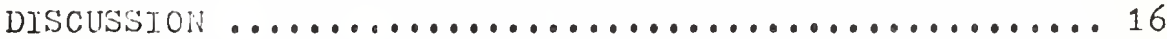

Pertinent Kinetic Equations...................16

Experinental Problems and Assumptions.......... 18

Agrecment of Results with Those of Other:

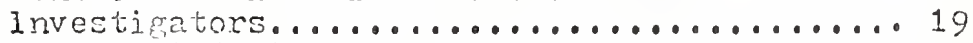

Chemical or Diffusion Control................20

Effect of Adrixtures on the Velocity........... 23

Efiect of Admixtures on Apparent Kate Constants... 24 .

Effect of Admixtures on the Activation Energy....2 25

Effect of Admixtures on the Ratio K' $/$ T..........27

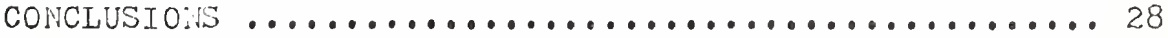

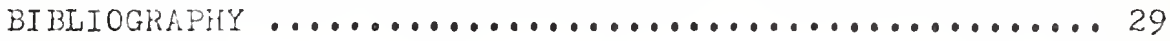

APPINDICES

Appendix $\Lambda$ : Sample Calculation............. 31

Appendix B: Derivation of Relatjonship Between

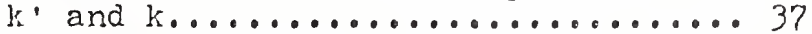

Appendix C: Calculation of Decrease in Acidity

During a Run...................40 
Digitized by the Internet Archive in 2011 with funding from

LYRASIS members and Sloan Foundation; Indiana Department of Transportation 


\section{IIST OF TABLES}

Table

Page

1.

Proprietary Retarders

2. Summary of Reaction Velocities With and Without Admixtures .................. 14

3. Summary of Solution Viscosities and k'y/T Values for the Temperatures in Question With and Without Admixtures.............

4. Summary of Apparent Rate Constants, Activation Encrgjes, and Frequency Factors for the Calcite Dissolution Reaction Vith

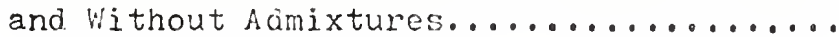




\section{IIST OF FIGURES}

Figure

1. $\mathrm{CaCO}_{3}$ Dissolution Apparatus.............. 10

2. Velocity of Reaction at $15.0^{\circ} \mathrm{C} \ldots \ldots \ldots . . . .32$

3. Velocity of Reaction at $25.0^{\circ} \mathrm{C} \ldots \ldots \ldots . \ldots 33$

4. Velocity of Reaction at $35.0^{\circ} \mathrm{C} \ldots \ldots \ldots . . .34$

5. Determination of Rate Constant (k')..... 35

6. Determination of Activation Energy $\left(E_{2}\right) \ldots 36$ 
ABSTRACT

Muszynski, Larry Chester. M.S., Purdue University, August 1973. Kinetics of Calcite Dissolution. Major Professor: Dr. W. L. Dolch.

The kinetics of the dissolution of calcite in dilute hydrochloric acid $(0.0184-0.0364 \mathrm{M})$ were studied at these temperatures, $15^{\circ} \mathrm{C}, 25^{\circ} \mathrm{C}$, and $35^{\circ} \mathrm{C}$. Velocities, rate constints, and activation energies were determined. The influence of varicus substances, including proprietary retarders and other reagents that are influential in controlling the rate of setting of portland cement were studied. In the absence of admixtures the rate constant was $1.99 \times 10^{-6} \mathrm{Iit} / \mathrm{sec}-\mathrm{cm}^{2}$, and the activation energy was $5.33 \mathrm{kcal} / \mathrm{mole}$.

Admixtures, and especially the commercial retarders, decreased the reaction velocities and rate constants. The activation onergies were generally increased, in some instances Ereatly, to a maximum of $13.2 \mathrm{kcal} / \mathrm{mole}$. The pce-aponential factors in the Arrhenius equation were also greatly changed in some instances. It is concluded that the presence of the proprietary retarders can cause a change in the nature of the rate-determining step of the reaction studied. 


\section{INPRODUCTION}

Any material other than water, aggregate, and hydraulic cemcrit that is used as an ingredient of a concrete mixture and is added immediately before or during its mixing is defined as an admixture. This excludes materials interground or interblended with the hydraulic cement. An admixture is used to make the concrete more suitable for the purpose for which it is made or to reduce its cost.

One imporiant class of admixtures is retarders, which are used principally to delay the setting time, although they bring about other beneficial changes as well. Retarders can compensate for adverse conditions, particularly in hot weather concreting. Retarders are in increasingly common use and are being used presently in 50 to 60 million cubic yards of concrete per year.

Commercial retarders are usually classified into three chemical categories:

1) Ijgnosulforic acids and their salts,

2) hydroxycarboxylic acids and their salts,

3) carbohydrates (sugars).

Their mode of action is largely unknown. Their retarding action is said to be duc to some kind of physical and/or 
chemical reaction. One possible effect is a change in the kinetics of the cement hydration reactions. Other theories of retardation postulate physical changes, such as the formation of a "coating" on the cement grains to protect them from attack by the water, or some change in the morphology of the hydration products. But these theories do not exclude a possible change in the kinetics of the reaction itself.

So the retardation can be explained, at least partly, by a rate change or a change in the activation energy of the process. The activation energy is the energy that a molecule must possess before it can react with another molecule upon collision, and is a basic parameter of chemical kinetics.

The hydration of portland cement involves complex simultaneous and competing reactions of several components of the cement with water. The so-called "through-solution" hypothesis implies that the dissolution of these components is a major step in the hydration process. For the compounds $\beta-\mathrm{C}_{2} \mathrm{~S}$ and $\gamma-\mathrm{C}_{2} \mathrm{~S} *$ there is an indication (1) that the rate-determining step in the hydration is the protonation of the surface silicate ion of the anhydrous solids.

* In this report the conventional shorthand of cement chemistry is used, $\mathrm{C}=\mathrm{CaO}, \mathrm{S}=\mathrm{SiO}_{2}, \mathrm{~A}=\mathrm{Al}_{2} \mathrm{O}_{3}, \mathrm{~F}=\mathrm{Fe}_{2} \mathrm{O}_{3}$, $\mathrm{H}=\mathrm{H}_{2} \mathrm{O}$, etc. 
The aim of the present work, therefore, was to study a reaction that is simpler but is thought to proceed by the same mechanism as the cement hydration, and that has been studied comparatively thoroughly. The effects of retarding admixtures on the rate of such a "model" reaction could be determined and applied by analogy toward the more complex cement hydration system.

A simple, first order, heterogeneous, chemicallycontrolled reaction, whose rate-determining step is thought to be the same as that of the cement hydration reaction, that is, protonation, of the surface oxygens, is the dissolution of calcite $\left(\mathrm{CaCO}_{3}\right)$ by dilute strong acids.

The present paper discusses the results of experiments undertaken to gain information concerning the influence of retarders, both proprietary substances and pure chemicals, on the rate of dissolution of calcite by dilute $\mathrm{HCl}$. 


\section{LITERATURE REVIEW}

Chemical reactions proceed at a rate that is a function primarily of the concentration of the reactants and the temperature. The determination of the extent of reaction as a function of time, concentration of species present and temperature permits, in principle, the calculation of the rate constants and the activation energy of the process (2). The latter, in turn, is indicative of the molecular mechanisms that are taking place. Such determinations are complicated by competing reactions, sequential reactions, and physical rate processes such as diffusion phenomena. In the case of scquential reactions, the slowest step is rate-controlling, and the calculated activation energy is indicative of the mechanism of this slowest reaction.

The mechanism of the hydration of cement is largely unknown, primarily because several reactions are taking place simultaneously and sequentially and because molecular diffusion may play an important role. The state of knowledge is reviewed by Kondo and Ueda (3). The kinetics of the hydration of alkaline-earth orthosilicates were studied by Campbell (1) who postulated that a rate-determining step for $B-C_{2} S$ and $\gamma-C_{2} S$ is the protonation of a surface silicate ion In the solid, or more specifically, the oxygen atoms. Weyl (4) 
has postulated the same sort of mechanism for the dissolution of carbonates such as calcite and magnesite by dilute acids.

The rate constants for the dissolution of calcite have been reported by several workers whose results were summarized by Moelwyn-Hughes (5). These early results have been confirmed by Bassow et, al. (6), who obtained an activation energy of $6.4 \mathrm{kcal} / \mathrm{mole}$ for the $\mathrm{CaCO}_{3}-\mathrm{HCl}$ reaction. Tominga, Adzumi, and Isobe ( 7 ) corrected for the fact that the viscosity of the solution decreases as the temperature increases, thus increasing the velocity of the reaction which they claimed to be inversely proportional to the viscosity of the solution. This correction gave a value for the activation energy of $5.4 \mathrm{kcal} / \mathrm{mole}$. These workers studied systems that were stirred rapidly to eliminate the effects of diffusional barriers. Whether the objective was achieved by their method of stirring is conjectural.

Spring (8) was the first to establish that the rate of dissolution of marble by dilute acids is unimolecular. Brunner (9) showed that marble dissolves faster in strong acids than does magnesite. Palmaer (10) found that Iceland Spar, another form of calcite, was not as suitable as marble because of the many minute fissures found in the surface after cleavage fracture of the crystals, thus 
yielding different velocities of $\mathrm{CO}_{2}$ evolution for different crystallographic faces of the crystal.

King and Liu (11) supported the diffusion theory as applied to the rate of dissolution of ealcite in dilute acids. The diffusion theory holds that the ratedetermining step is either the diffusion of the products from the surface of the solid to the bulk solution or, as the Nearnst theory contends, the diffusion of the solute to the solid surface. They also contended that additives, such as sucrose, affect the reaction rate by increasing the viscosity of the solution and thus changing the diffusion rates.

Tominga, Adzumi, and Isobe (7) claimed that the chemical reaction is rapid at the solid surface, and that the reaction follows Nearnst's theory of diffusion of the solute through the product layer. Moelwyn-Hughes (5) pointed out that the diffusion theory fails to explain why calcite dissolves much faster in dilute HCl than magnesite or dolomite. Also it would be reasonable to expect marble and Iceland Spar to dissolve at the same rate if diffusion governs the rate process, which according to Palmaer (10) is not the case. Moelwyn-Hughes (2) also pointed out the illogic of applying, to reactions carried out with violent stirring, the diffusion coefficient determined in unstirred solutions. Centnerszwer and 
Heller (12) concluded that at high stirring speeds the acid reaches the surface of the solid faster than it can react, and the diffusion layer consequently disappears. Barrow et. al. (6) claimed that low HCl concentration $(\sim 0.05 \mathrm{M})$, fast stirring speeds ( $\sim 900 \mathrm{r.p.m.})$, small particle size $(\sim 20 \mathrm{mesh})$, and low temperature $\left(\sim 35.0^{\circ} \mathrm{C}\right)$ all tend toward a chemically controlled reaction.

The reaction in question consists of the removal of carbonate ions from the crystal, presumably

$$
\mathrm{CO}_{3}=+\mathrm{H}_{3} \mathrm{O}^{+}=\mathrm{HCO}_{3}^{-}+\mathrm{H}_{2} \mathrm{O}
$$

The subsequent decomposition of the bicarbonate ion

$$
\mathrm{HCO}_{3}^{-}+\mathrm{H}_{3} \mathrm{O}^{+}=\mathrm{CO}_{2}+2 \mathrm{H}_{2} \mathrm{O}
$$

is thought to be rapid, so that reaction (1) is ratecontrolling. According to this mechanism one molecule of $\mathrm{CO}_{2}$ is produced for each hydrogen ion that disappears as a result of colliding and reacting with the solid surface and the reaction is thereby unimolecular. 
EXPERIMENTAI WORK

\section{Materials}

Marble chips were used as the calcite. They were ground in a mortar and pestle, sieved between the No. 16 and No. 30 sieves, washed with distilled water on the sieve, and oven-dricd on the sieve at $110^{\circ} \mathrm{C}$. After drying, the crushed marble was sieved again, washed again, re-dried, and bottleo.

The calcium and magnesium contents of the marble were determired by dissolution in $\mathrm{HCl}$ and complexometric titration in the usual way. The result, for the marble from Fisher Chemical Co., was $99.25 \% \mathrm{CaCO}_{3}$, and $0.39 \%$ $\mathrm{M}_{3} \mathrm{CO}_{3} \cdot$

Dilute HCl was made up in 5 gallon carboys and standardized against $\mathrm{Na}_{2} \mathrm{CO}_{3}$, usirg methyl red. The .. standerdizations yielded acid strengths of $0.0184 \mathrm{M}, 0.0274 \mathrm{~m}$, and $0.036 /$ in.

The admixturos used rere:

Citrj.c Acid nonohydrato, reacent erade. Sucrose, reasent srade. Givengol, virificd crade. Cid.ciun chlorido, ronrent éradc.

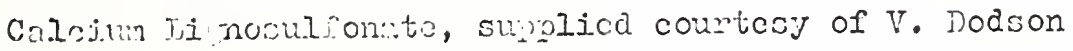


Three proprietary retarders, each representing one of the three major classes of these materials, were used. They are referred to by code letters as follows (Table 1).

Table 1

Proprietary Retarders

Code

Letter

Type

Density, g/cc.

Solids

L Lignosulfonate

1.147

32.2

A Hydroxycarboxylic acid

1.152

32.6

S Carbohydrate

1.175

35.1

\section{Apparatus \& Procedure}

The rates of the calcite dissolution reaction were determined by using the apparatus shown in Figure 1.

The reaction flask was immersed in a constanttemperature water bath controlled at temperatures of $15^{\circ}$, $25^{\circ}$, and $35^{\circ} \mathrm{C} \pm 0.01^{\circ} \mathrm{C}$.

The reaction flask was stirred internally with a submersible magnetic stirrer (Henry Troemner, Inc.) operating at about $900 \mathrm{rpm}$.

The reaction flask was connected by Tygon tubing to a three-way stopcock with one side free to the atmosphere 


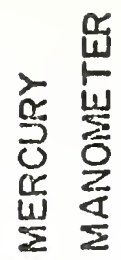

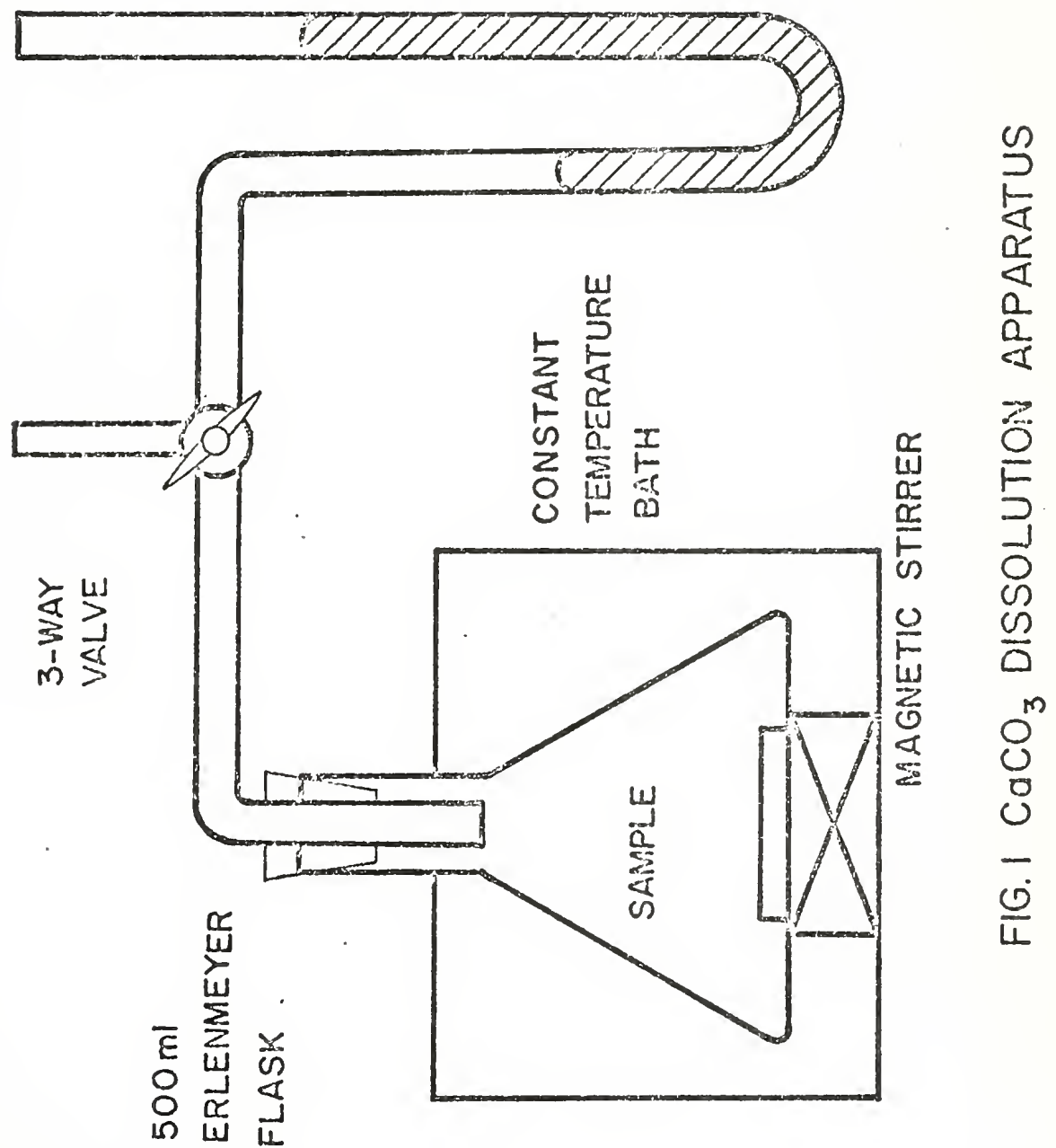


and the third side attached through another piece of Tygon to a mercury manometer, $6.0 \mathrm{~mm}$ i.d. The manometer was read by means of an attached scale.

To start a run, at a specific temperature and $\mathrm{HCl}$ concentration, $400 \mathrm{ml}$ of acid were introduced into the flask and stirred for 15-20 minutes to allow the solution to come to temperature equilibrium with the bath. The stopcock was positioned so that both the flask and the manometer were open to the atmosphere.

Then the sample, $2.50 \pm 0.01 \mathrm{~g}$ of the crushed marble, was added to the flask, the stopper was immediately inserted, and the timer was started.

At this zero of time for the run the system was at atmospheric pressure because of the stopcock position. Immediately then, the stopcock was turned to connect flask and manometer. The time for the accomplishment of these initial operations was only 2 or 3 seconds.

Then as the reaction proceeded its course was followed by taking readings of the pressure change in the manometer as a function of time. Readings were usually taken at intervals of $\Delta \mathrm{P}$ of five torr. For slower reactions, as with admixtures $L$ and $A$, readings were taken at intervals of three torr.

The readings were continued to a maximum pressure difference of about 40 torr, but usually it was less. 
The run thus corresponded to the consumption of only a few percent of the acid present, as will be shown later (Appendix C).

Duplicate runs were made on the control reaction (i.e., no admixture) but not on those containing the admixture. To a certain extent, of course, the regular program of runs for each solution contained an internal check on reproducibility by the requirement of linearity of the plots from which the activation energies were calculated.

The viscosity of each solution, including those with admixtures, was determined using a falling-ball viscometer with a stainless-steel ball. The estimated accuracy was 1 or 2 percent. The constant for the apparatus was determined by duplicate measurements on water.

Admixture concentrations in the reacting solutions were either 0.25 percent or 1.0 percent (weight of solids in admixture/ volume of reacting acid solution). 
DATA

The data from the kinetic measurements are presented in Table (2) as reaction velocities, which are the slopes of plots of pressure change in the reaction flask vs. time. These velocities were determined at three tempcratures, 15,25 , and $35^{\circ} \mathrm{C}$ and at three acid concentrations, $0.0184 \mathrm{~m}, 0.0274 \mathrm{~m}$, and $0.0364 \mathrm{im}$.

Table (3) gives a summary of the viscosities of the solution with and withoui admixtures at the three differcnt temperatures and with an acid concentration of $0.0274 \pi$, which is the median concentration of the three used. 


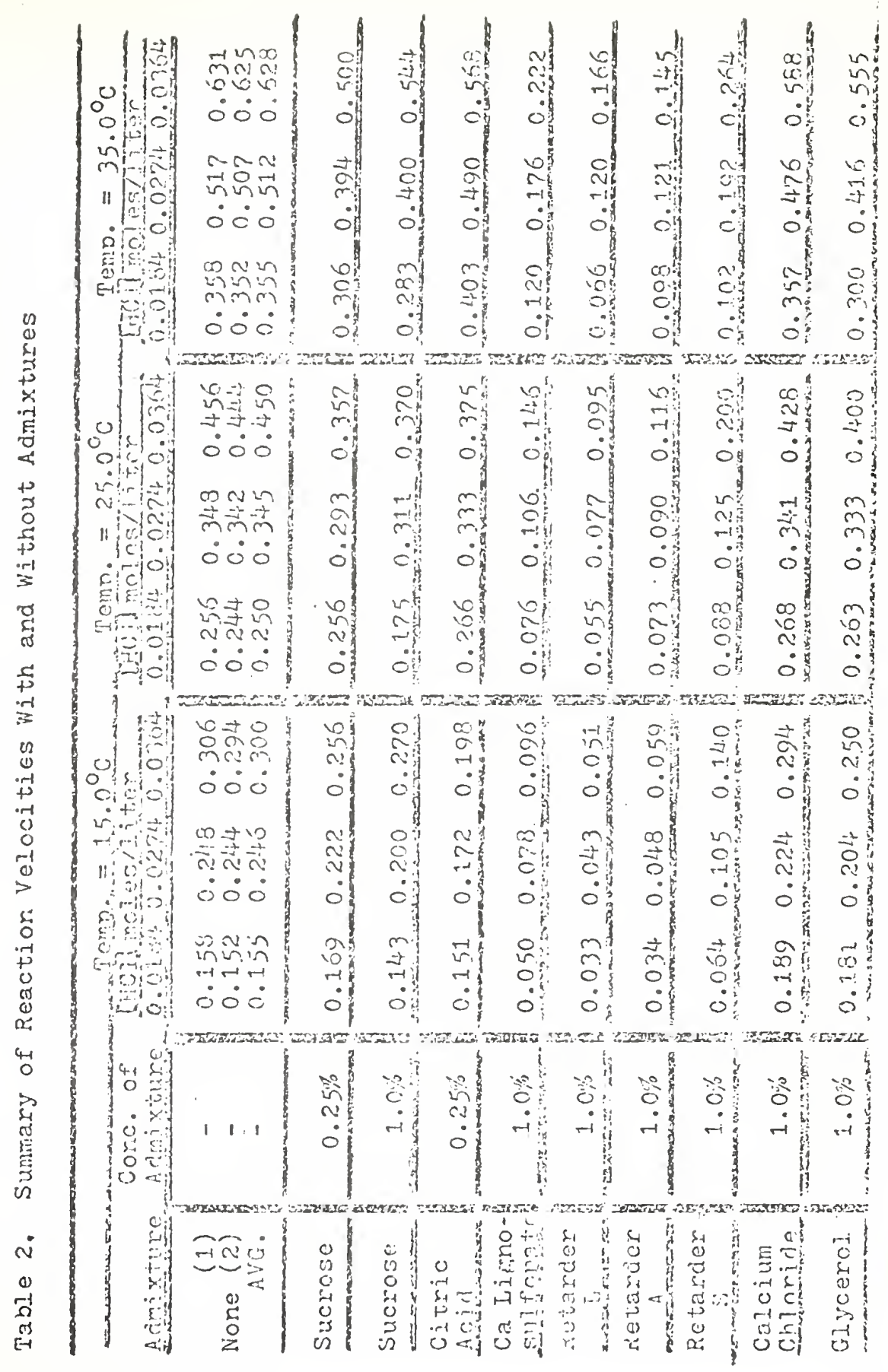




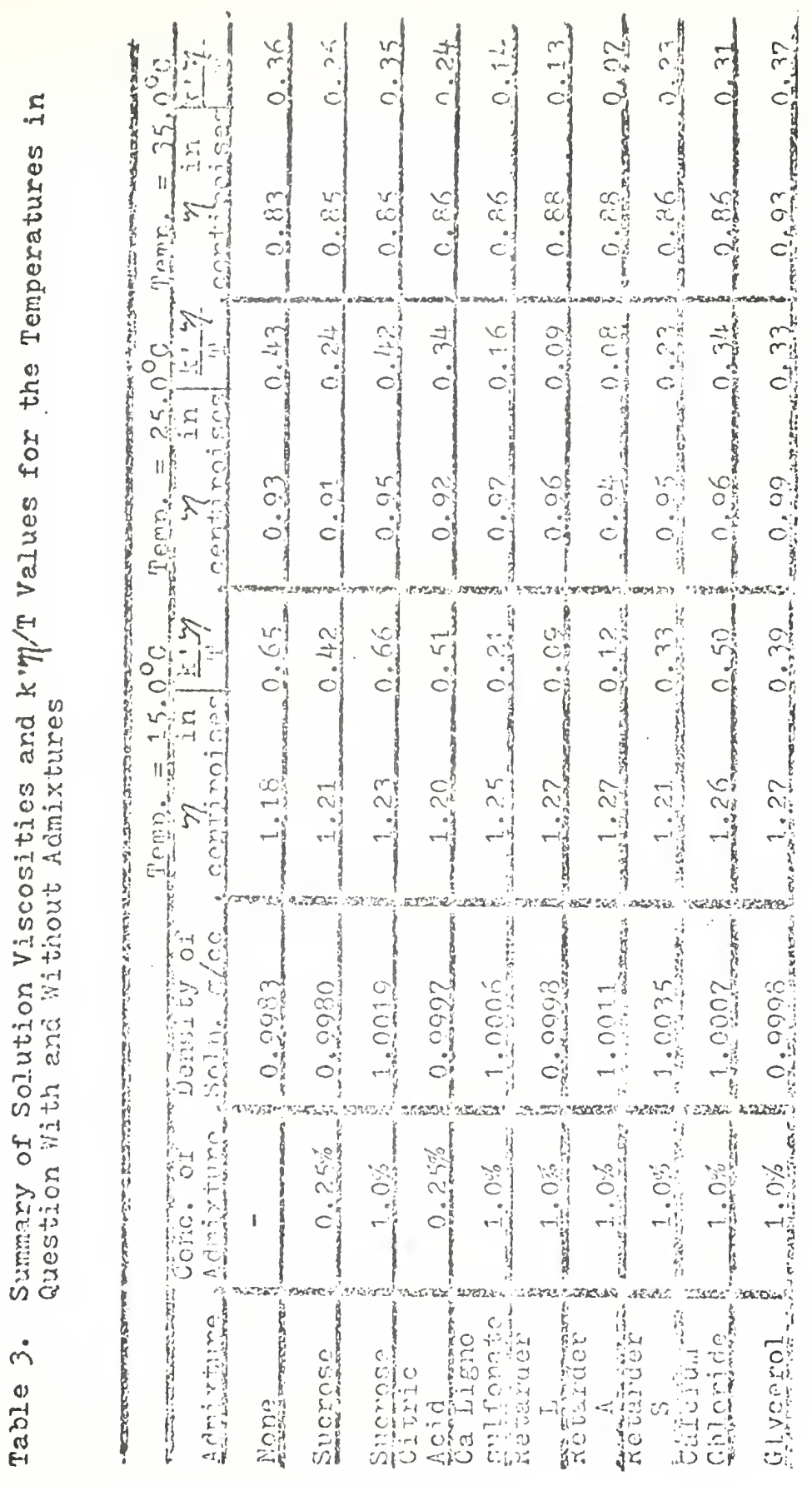




\section{DISCUSSION}

\section{Pertinent Kinetic Equations}

The data were taken in the form of change in pressure in the reaction flask, as read on the manometer, vs, time. The slope of such a plot is the reaction velocity, $v=d p / d t$ in units of torr/sec. These values were presented in Table(2).

When $v$ is plotted as a function of acid concentration at constant temperature the slope of the curve is the apparent rate constant, k', defined by

$$
\frac{d p}{d t}=k \cdot\left[\mathrm{H}^{+}\right]
$$

and with units of torr-Iit/mole-sec. The apparent rate constants are given in Table (4).

The activation energy is deternined by plotting the logarithm of the rate constant against reciprocal temperature. The slope of such a plote is the apparent activation energy divided by the gas constant according to

$$
k^{\prime}=A \exp \left(-E_{a} / R^{\prime} I^{\prime}\right)
$$

which is the Arrhenius equation. The calculated activation energies are also given in Table (4). 


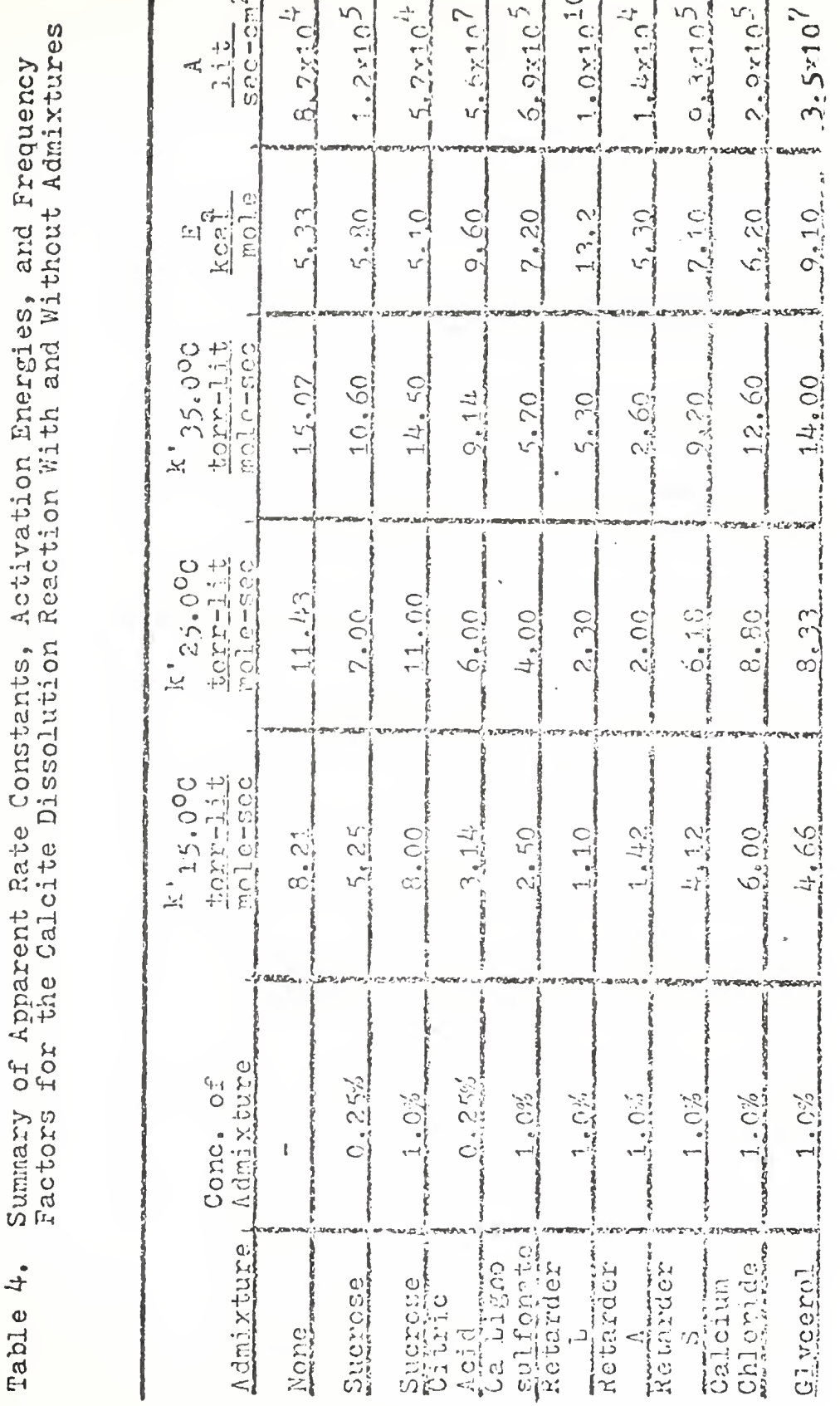


A complete calculation, including appropriate curves, is given in Appendix A for the control, or no-admixture, data. The method of calculation for the other runs was identical.

Heterogeneous reactions in solution are influenced by the extent of solid surface present. Moelwyn-Hughes gave the rate contant of this dissolution as proportional to the first power of the surface area. Therefore, a true, as opposed to an apparent, rate constant can be defined by

$$
\frac{d \mathrm{CO}_{2}}{\mathrm{dt}}=\mathrm{kS}\left[\mathrm{H}^{+}\right]
$$

where the rate constant, $k$, has the dimensions $l i t . / \mathrm{sec}-\mathrm{cm}^{2}$ or, more generally, $\mathrm{cm} / \mathrm{sec}$ and $\mathrm{n}_{\mathrm{CO}_{2}}$ is the moles of $\mathrm{CO}_{2}$ evolved during the reaction. The relationship between $k$ and $k^{\prime}$ is derived in Appendix $B$. The linear nature of this relationship makes the use of either $k$ or $k$ ' a valid route, via the logarithm, for the determination of the activation energy.

\section{Experimental Problems and Assumptions}

One problem was the change in the acid concentration of the solution as $\mathrm{CO}_{2}$ was evolved and acid was used up. An analysis of this matter is given in Appendix $C$. The results illustrate that the maximum reduction in acid 
strength is about $5 \%$, but the effects on the determination of $\mathrm{k}^{\prime}$ are less because all points will be moved in the same direction on the plot of $\mathrm{v}$ vs. [H] and, therefore, the slope will be little affected.

Another problem concerns the value of specific surface used to determine the total surface area of the marble sample used. The derivation given in Appendix $B$ assumes the particles to be cubes with an edge dimension equal to the algebraic mean of the two sieve sizes. Such a model has obvious deficiencies. The "true" surface area is no doubt larger than the one so calculated, probably by several times, because of surface roughness. But the same problem and relative error was no doubt encountered by others who did similar experiments, so a comparison of these results and theirs on this basis is probably valid. The reproducability of the measurements is shown in Table(2) for the control reaction, no admixture, in which duplicate runs of $\mathrm{dp} / \mathrm{dt}$ yielded a difference of only $2 \%$ from the mean value. The $\mathrm{k}^{\prime}$ and $\mathrm{E}_{\mathrm{a}}$ values in Table (4) were calculated from the mean values of $\mathrm{dp} / \mathrm{dt}$.

\section{Agreement of Results with Those of Other Investigators}

When the results of other workers are calculated in terms of equation (5) the following $k$ values, in lit/sec-cm, are obtained: Bassow et. al. (6), $2.31 \times 10^{-6}$; 
Tominga et. al. (7), $3.6 \times 10^{-6}$; and King and Liu (11), $2.8 \times 10^{-5}$, all at $25^{\circ} \mathrm{C}$.

The value obtained in the present work was $1.99 \times 10^{-6}$ lit/sec-cm ${ }^{2}$ (Appendix B), which agrees reasonably well with the first two values mentioned above, but not with the third, by an order of magnitude. The reason for such a difference is not known.

The activation energies for the control reaction vary somewhat from the results of others. Barrow et. al. obtained a value for $\mathrm{E}_{\mathrm{a}}$ of $6.4 \pm 0.3 \mathrm{kcal} / \mathrm{mole}$; $\mathrm{King}$ and Liu obtained a value of $5.82 \pm 0.77 \mathrm{kcal} / \mathrm{mole}$. Tominga et. al. accounted for viscosity effects, that is changing the temperature from $15^{\circ} \mathrm{C}$ to $35^{\circ} \mathrm{C}$ decreases the viscosity of the solution, and obtained a value of $5.4 \pm 0.2 \mathrm{kcal} / \mathrm{mole}$. The value obtained in the present work was $5.33 \pm 0.3$ $\mathrm{kcal} / \mathrm{mole}$ (Table 4), which agrees with the work of Tominga et. al, and is within the limits of the value determined by King and Iiu. The $\mathrm{E}_{\mathrm{a}}$ value of Barrow et. al. is an order of magnitude greater than the value obtained in the present work.

\section{Chemical or Diffusion Control}

There are several parameters from which one can decide whether a reaction is chemically controlled or diffusion controlled. Moelwyn-Hughes $(2,5)$ illustrates 
five such. One is $\mu$, the mobility of the hydrogen ions as they approach the solid surface. This mobility can be calculated from the equation

$$
k=\mu \exp \left(-E_{a} / R T\right)
$$

Another parameter is $\delta$, the thickness of thelperhaps fictitious) diffusion layer, calculated from the vermot equation $\mathrm{k}_{1}=\mathrm{D} / \mathrm{S}$ where $\mathrm{D}$ is the coefficient of diffusion. Another test is the influence of temperature on the velocity of the reaction. The coefficient $\mathrm{dk} / \mathrm{dT}$ should equal $\mathrm{dD} / \mathrm{dT}$, and the increment of energy should be $4.5 \mathrm{kcal} / \mathrm{mole}$ for a diffusion controlled reaction. This is the differential of the liernst equation with respect to temperature. Another characteristic of reactions governed by diffusion is that the value of $k$, the rate constant, varies with stirring speed. Lastly, if the ratio $\mathrm{k} / \mathrm{m} / \mathrm{T}$ is constant, the velocity would be diffusion controlled, since in the diffusional process the rate constant shows a linear dependence on temperature, whereas for a chemically controlled process the rate constant is exponentially dependent on the temperature.

From the value of $\mathrm{k}$ obtained in the present work, $1.99 \times 10^{-6} \mathrm{lit} / \mathrm{sec}-\mathrm{cm}^{2}$, the value for the mobility of the hydrogen ions was calculated using $5.33 \mathrm{kcal} / \mathrm{mole}$ for the value of $E_{a}$. The calculated mobility of the hydrogen ions in the solution was $13.7 \mathrm{~cm} / \mathrm{sec}$. 
The calculated thickness of the diffusion layer o $\delta$, using the CRC Handbook value for the diffusion coefficient, was $1.5 \times 10^{-2} \mathrm{~cm}$.

The temperature coefficient of the rate constant, $\mathrm{dk} / \mathrm{dT}$, had an energy increment of $5.33 \mathrm{kcal} / \mathrm{mole}$, i.e., the activation energy.

The ratio $\mathrm{k}$ '少/ for the temperatures $15.0^{\circ} \mathrm{C}, 25.0^{\circ} \mathrm{C}$, and $35.0^{\circ} \mathrm{C}$ were given in Table (3) and found not to be constant for the control reaction.

The following conclusions can be drawn from these results. A hydrogen ion mobility of $13.7 \mathrm{~cm} / \mathrm{sec}$ is too fast to be part of a diffusional process. A layer thickness of $0.15 \mathrm{~mm}$, about $20 \%$ of the diameter of the particle, is so large as to border on the physically impossible. The critical increment of energy, $5.33 \mathrm{kcal} /$ mole, is larger than the maximum energy for diffusional reactions, $4.5 \mathrm{kcal} / \mathrm{mole}$. When these figures are converted to the appropriate exponentials the larger represents a rate one fourth that of the smaller.

The above results indicate that, for the conditions used here, the rate of the calcite dissolution is chemically, rather than diffusionally, controlled if no admixture is present. 


\section{Effect of Admixtures on the Velocity}

In general, both the pure chemical and proprietary retarders reduced the velocity of the reaction, as show in Table (2). The $0.25 \%$ sucrose showed a slight accelcrating effect at the low $\mathrm{HCl}$ concentrations and low temperatures. $\mathrm{CaCl}_{2}$, which is an accelating admixture for concrete, showed an accelerating effect at low $\mathrm{HCl}$ concentrations at any temperature. Glycerine, which has no effect in concrete, behaved as $0.25 \%$ sucrose.

Calcium lignosulfonate and the proprietary retarders, I, S, and A retarded the velocity by $60-70 \%$, while the pure chemical retarder, e.g. sucrose, retarded the velocity by only $5-10 \%$. It is perhaps significant that the proprietary retarders had a much greater influence on the reaction velocity than did any of the pure chemical specjes. Retarder $L$ and Retarder A appear to retard better than Retarder $S$ and purified calcium lignosulfonate. Retarder I reportedly contains lignosulfonate salts plus sugar derivatives.

Reference to Figures 2, 3, and 4 shows that a period of about 20 seconds clapsed before gas evolution began, 
as show by the intercept of the curves on the time axis. This induction period was not greatly affected by any of the admixtures.

\section{Effect of Admixtures on Apparent Rate Constants}

The apparent rate constant $k^{\prime}$, as stated previously, was obtained from the slopes of the curves of dp/dt, the velocity, vs. the $\mathrm{HCl}$ concentration at the three temperatures $15.0^{\circ} \mathrm{C}, 25.0^{\circ} \mathrm{C}$, and $35.0^{\circ} \mathrm{C}$. The rate constant can be thought of as a measure of the extent of the reaction at unit time and concentration.

It can be noted from Table (4), that the addition of the admixtures result in reduced apparent rate constants. That is, all the admixtures made the dissolution less sensitive to changes in acid concentration. The proprietary retarders and calcium lignosulfonate, again, reduced the apparent rate constant to a much greater degree than did the pure chemical substances.

This near-universal reduction in the rate of the reaction and in its sensitivity to acid by the admixtures, and especially by the proprietary retarders, is probably significant. 


\section{Effect of Admixtures on the Activation Energy}

The effect of the admixtures on the activation energy of the reaction is shown in Table (4). The values range from $5.1 \mathrm{kcal} / \mathrm{mole}$ to $13.2 \mathrm{kcal} / \mathrm{mole}$, and are, in general, larger than the value for the control reaction. The implication of these results is that different processes become rate-controlling when some admixtures are present.

A difficulty is the question of the variability in $E_{a}$ due to ordinary experimental error. A trial calculation shows a 10 percent error in one of the $k^{\prime}$ values, most improbably large, to result in a change in $\mathrm{E}_{a}$ of $1 \mathrm{kcal} / \mathrm{mole}$. So any differences in $\mathrm{E}_{\mathrm{a}}$ substantially smaller than this can probably not be attributed to differences in mechanism of the slow reaction.

The run with citric acid may be anomalous, because citric is apparently a strong enough acid to dissolve calcite by itself (11). So the result with citric acid may reflect a combined action.

The other $E_{a}$ values can perhaps be grouped as follows: sucrose, Retarder $\mathrm{A}, \mathrm{CaCl}_{2}$ - about the same as the control reaction; Retarder $S$ and calcium lignosulfonate; glycerine; Retarder L.

If the same molccular process is occurring as the slow and rate-determining step in the reactions, the $E_{a}$ should be the same. A necessary influence is, therefore, 
that those reactions that yielded appreciably higher values of $E_{a}$ have a different mechanism. What it may be cannot be determined from these data. The fact of a linear in $\mathrm{k}$, vs. 1/T plot argues for the same process occurring at the various temperatures in question, whatever it may be.

In Table (4) are also given the values of the preexponential factor, $A$, of the Arrhenius equation, $k^{*}=$ $A \exp \left(-E_{a} / R T\right)$. According to the collision theory, A is a factor proportional to the frequency with which reacting species collide with each other. It can be seen that the $A$ factor is greatly influenced by the presence of some admixtures, notably Retarder $L$. The implication is that the presence of Retarder L, and of gycerine as well, causes an increase in the rate of collision of the reacting molecules.

Campbell (1) found that the activation energies of hydration of $\beta$ - and $\gamma-\mathrm{Ca}_{2} \mathrm{SiO}_{4}$ were $11.4 \mathrm{kcal} / \mathrm{mole}$ and $16.1 \mathrm{kcal} / \mathrm{molc}$, respectively. The $5.33 \mathrm{kcal} / \mathrm{mole}$ activation energy in the control reaction is much less than the $\mathrm{E}_{\mathrm{a}}$ 's measured by Campbell, which can perhaps be accounted for by the different type of anion geometry between a silicate, $\mathrm{SiO}_{4} \overline{\text { }}$, tetrahedron and a trigonal carbonate, $\mathrm{CO}_{3} \overline{ }$, ion. This different Eeometry and/or the difference in nolarizability of the central atom, silicon and carbon respectively, may be responsible for the 
difference in the activation energy, for the mechanism of attack of the oxygen surface of the solid by the hydrogen ions of the acid.

\section{Effect of Adnixtures on the Ratiokin/m}

The viscosities of the solutions, with and without admixtures werc measured at $15.0^{\circ} \mathrm{C}, 25.0^{\circ} \mathrm{C}$, and $35.0^{\circ} \mathrm{C}$. The viscosities at the high temperature may be high due to some cooling, but the difference in the $\mathrm{k} / \mathrm{y} / \mathrm{T}$ ratio is less than $10 \%$ and can be neglected. Table (3) shows that for the retarders the ratios are not equal for. the low temperatures, $15.0^{\circ} \mathrm{C}$ to $25.0^{\circ} \mathrm{C}$ but become more so for the $25.0^{\circ} \mathrm{C}$ to $35.0^{\circ} \mathrm{C}$ range. Calcium lignosulfonate, glycerine, Retarder $I$, and Retarder $A$, have fairly constant ratios throughout the cntire temperature range, whereas the others are so only in the higher temperature range. The control reaction is not affected by the higher temperatures and thus, according to Moelwyn-Hughes (5), is a chemically controlled reaction, as stated previously. The others, however may tend toward diffusion control at $25.0^{\circ} \mathrm{C}$ to 35.08 , based on this criterion.

These results indicate a possible adsorption of the adnixture on the solid surface which tends to result in a diffusion controlled reaction, making diffusion of hydrogen ions to the surface or diffusion of products avay from the surface, the rate-determining step. 
CONCIUSIONS

The following conclusions seem reasonable, and are based on the materials used and the results of the experiments performed.

1. The proprietary substances ircluding calcium J.jenosulfonate that retard the hydration of portland cement have a stronfly jnhibiting efiect on the dissolution of calcite in dilite hydrochloric acid, as judged by changes in the velocities and rate constants of the reacion. A logical inference is that they do so by similar processes in the two systeris.

2. The presonce of the retarcicrs, in some instances, causcs large chaneses in the activation encreies and the pro-exponontial factors. A logical corclusion is that their presence causce different precesses to become rate-contiol? ing then these that control the reaction in their abserose. 
BI BLIOGRA PHY 


\section{BI BLIOGRAPHY}

1. Campbell, I. E., "Some Orthosilicates and Their Hydrates," Thesis, Purdue University, 1967.

2. Moelwyn-Hughes, E. A., "The Kinetics of Reactions in Solutions," Oxford University Press, Oxford, 1933.

3. Kondo, R. and Ueda, S., "Kinetics and Mechanisms of the Hydration of Cements," Fifth International Symposium on the Chemistry of Cement, Tokyo, Part 2, $203-255,1968$.

4. Weyl, W.A. and Marboe, E. C., "The Constitution of Glasses," Vol. 1, p. 88, John Wiley and Sons, Inc., 1962.

5. Moelwyn-Hughes, E. A., "Physical Chemistry," Second Ed., Pergamon Press, 1201-1205, 1961.

6. Bassow, H. et. al., "Study of the Physicai and Chemical Rates of Calciun Carbonate Dissolution in Hydrochloric Acid," J. Chem. Ed., 48, 327 (1971).

7. Tominga, H., Adzumi, H. and Isobe, T., "Viscosity Effect on the Rate of Solution of Calcium Carbonate in Hydrochloric Acid," Bull. Chem. Soc, Japan, 14, 348 (1939).

8. Spring, W., "Dissolution of Marble in Dilute Acids," z. Physika.1 Chem., 1, 209 (1887); 3, 13 (1888).

9: Brunner, "Dissolution of Viarble and Magnesia in Strong and Weak Acids," Z. Physikal Chem., 47. 79 (1904).

10. Palmaer, "The Corrosjon of Metals, "Ingeniorsvetenkapsakadamien, Handlingar, Stockholm, p. 40, 1929.

11. King, C. V. and Liu, C. L., "The Rate of Solution of Marble in Dilute Acids," J, Amer. Chem, Soc., 55. 1928 (1933). 
12. Centnerswwer and Heller, "The Effect of Stirring Speed on the Rate of Solution of Marble in Dilute Acids," Z, Physikal Chom, A 161, 116 (1932).

13. Ramachandran, V. S., "Action of Triethanolamine on the Hydration of Tricalcium Aluminate," Cement and Concrete Rescarch, Vol. 3, No. 1. 41 (1973).

14. Moelwyn-Hughes, E. A., "The Chemical Statics and Kinetics of Solutions," Academic Press, p.162, 1971. 
APPENDICES 
APPENDIX A 


\section{APPEINDX A \\ Sample Calculation}

Figures 2, 3, and 4 give the raw data for the control reaction, no adrixture. The reaction velocities were calculated from the slopes of the dp vs. dt plots at three djeferent Hicl concentrations $0.0184 \mathrm{~m}, 0.0274 \mathrm{iv}$, and $0.0364 \mathrm{~m}$, and at three different temperatures $15.0^{\circ} \mathrm{C}, 25.0^{\circ} \mathrm{C}$, and $35.0^{\circ} \mathrm{C}$.

Figure 5 shows the deternination of the apparent rate constants, for the control reaction, at the three temperetures in question. The rate constants are calculated from the slopes of the velocity vs. $\mathrm{HCl}$ concentration plots.

The activation energy of the control reaction is calculated from the slope in Figure 6, where the logarithm of the aprorent rate constants are plotted against the reciprocal of the absolute temperatures. The slope of the line is cqual to $-\mathrm{E}_{\mathrm{a}} / \mathrm{R}$, where $\mathrm{E}_{\mathrm{a}}$ is the activation cnergy and $\mathrm{R}$ is the gas constart. 


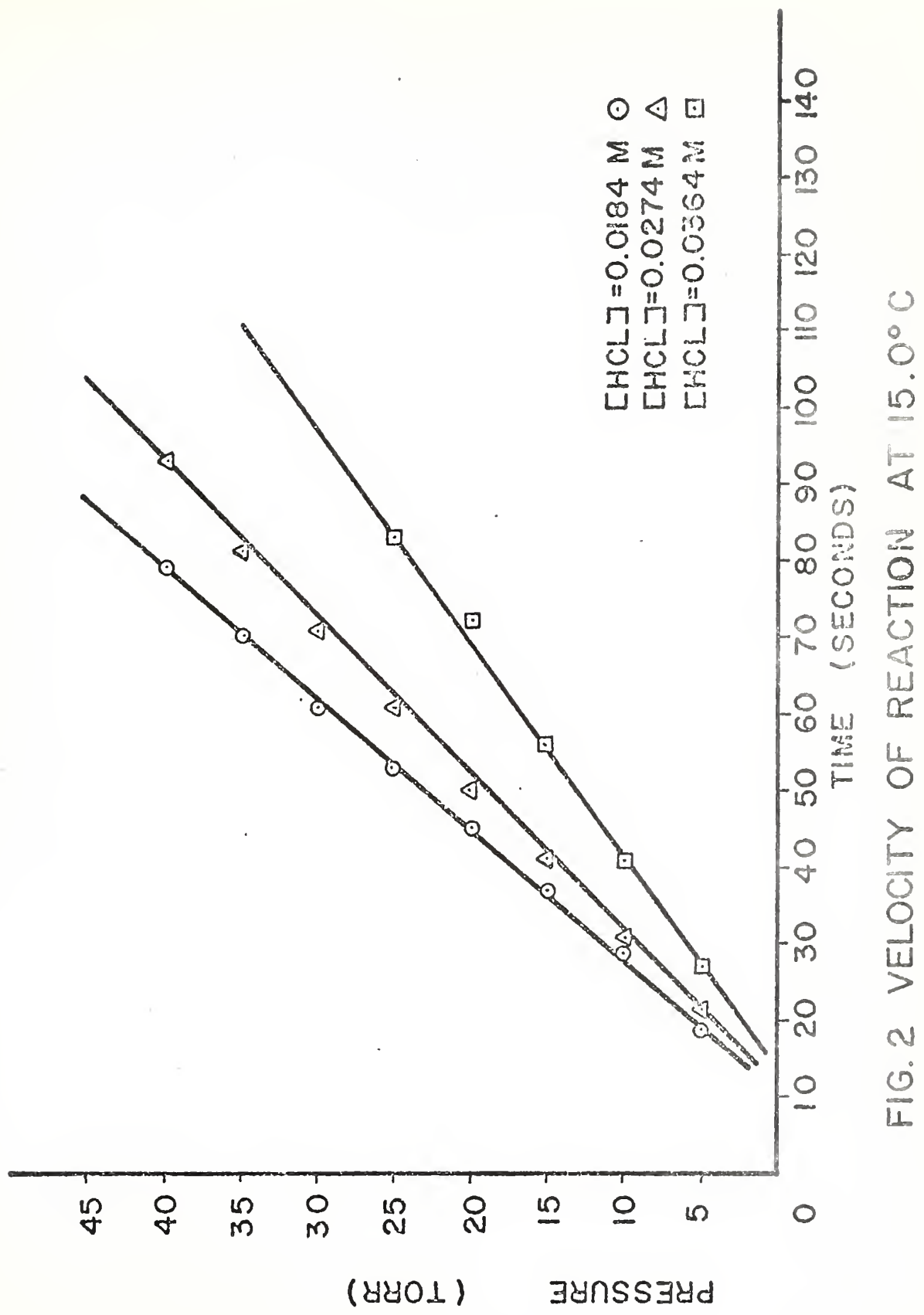




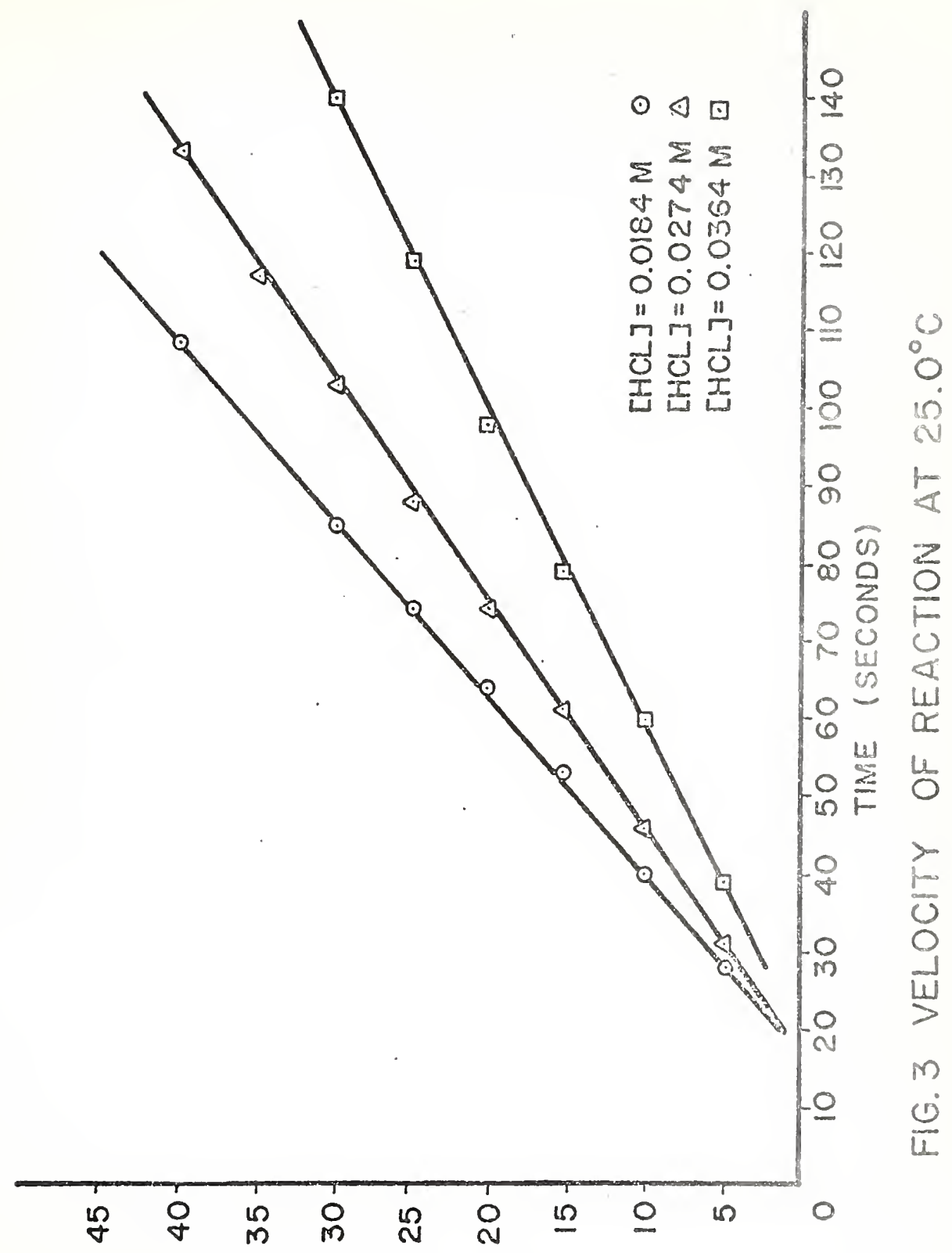

(4บO1) ㅂก 1) 


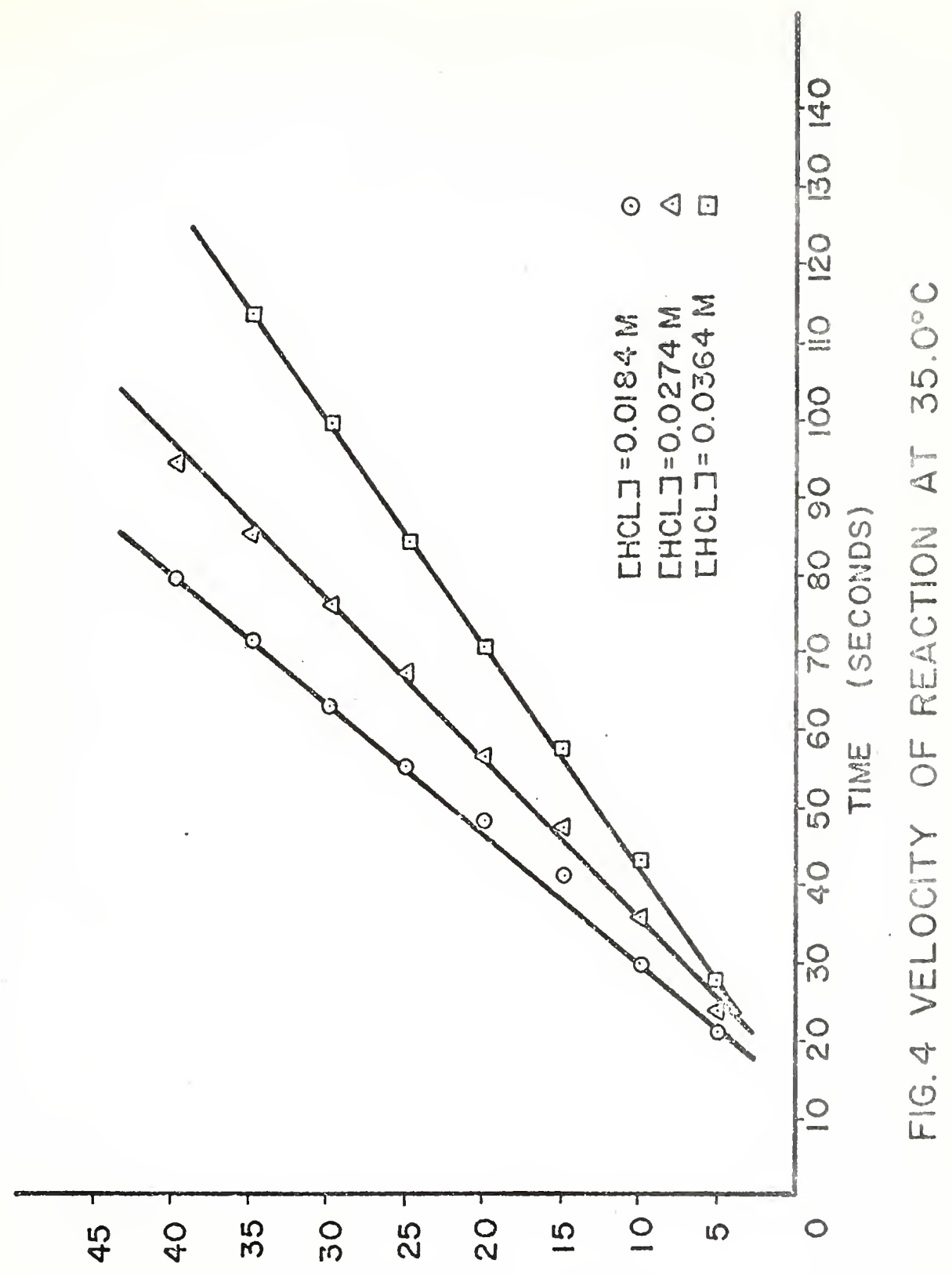

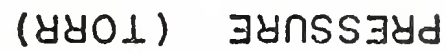




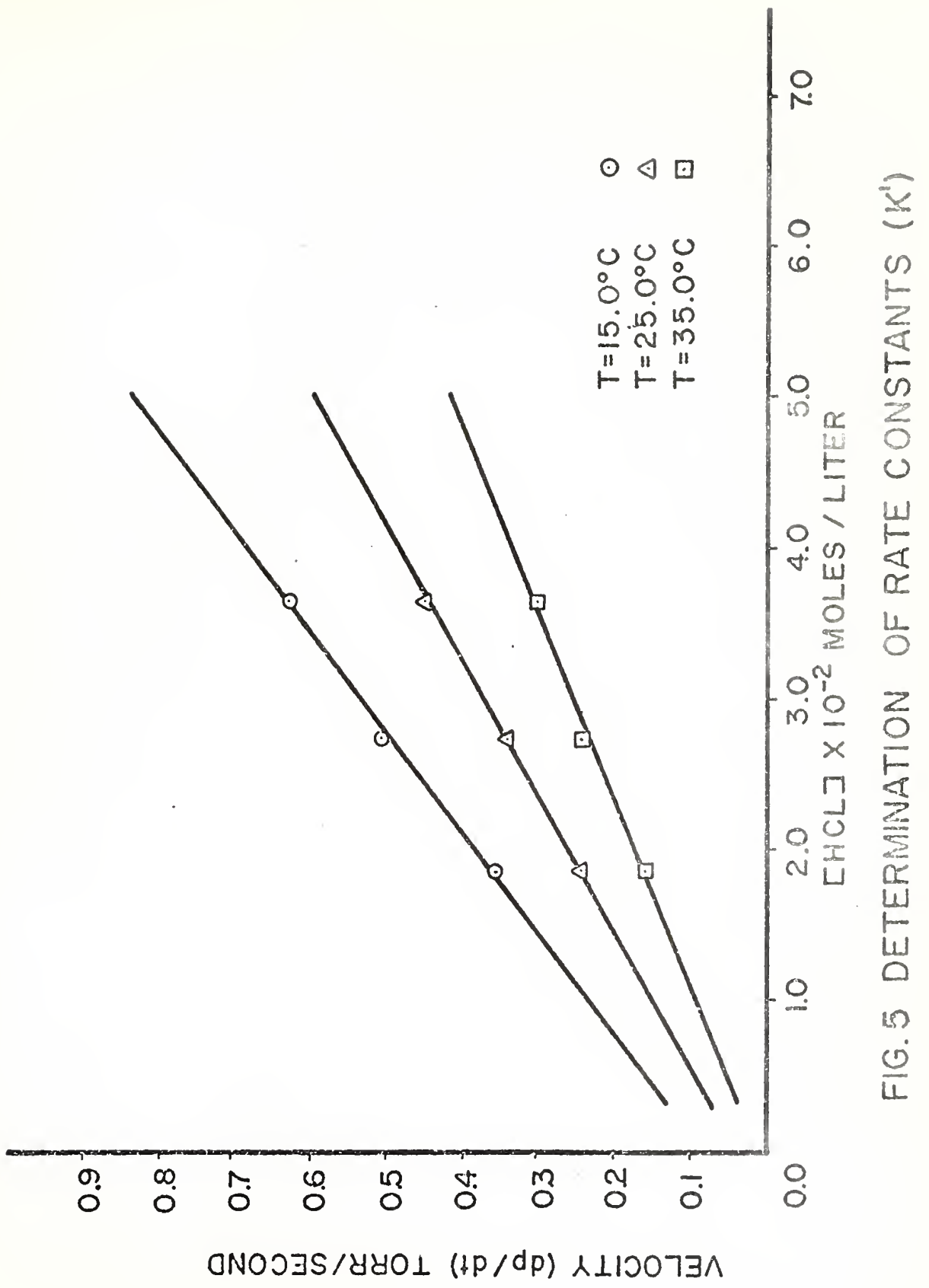




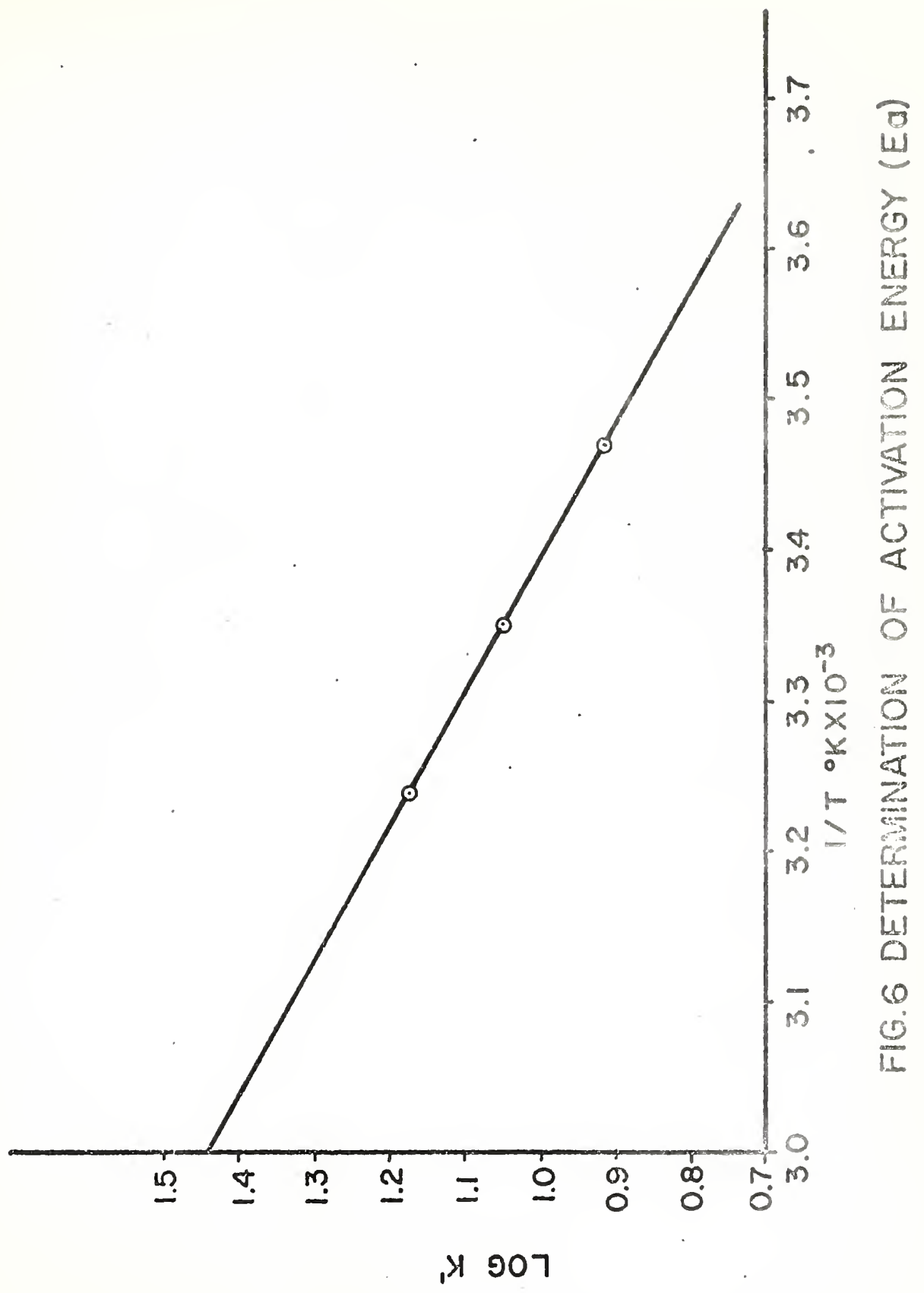


APPENDIX B 


\section{APPENDIX B}

\section{Derivation of Relationship Between $k$ and $k$}

The apparent rate constant, $\mathrm{k}^{\prime}$, is the slope of the plot of the reaction velocity vs. the concentration of $\mathrm{HCl}$,

$$
\mathrm{v}=\mathrm{dp} / \mathrm{dt}=\mathrm{k} \cdot\left[\mathrm{H}^{+}\right]
$$

The true rate constant is defined by

$$
\mathrm{dn}_{\mathrm{CO}_{2}} / \mathrm{dt}=\mathrm{kS}\left[\mathrm{H}^{+}\right]
$$

where $\mathrm{n}_{\mathrm{CO}_{2}}$ is the moles of $\mathrm{CO}_{2}$ evolved during the reaction. The relationship between the two can be derived as follows.

If the simple gas law is assumed to apply to all gases in the system, then at the start of the run, just after the system has been closed to the atmosphere

$$
\mathrm{p}_{\mathrm{o}} \mathrm{V}_{\mathrm{o}}=\mathrm{n}_{\mathrm{a}} \mathrm{RT}
$$

where $p_{0}$ is the pressure in the gas phase above the reactants at time zero, i.e. atmospheric, $v_{0}$ is the volume of gas (air) in the system at time zero, $n_{a}$ is the moles of air making up this volume, $R$ is the gas constant, and $T$ is the temperature. As $\mathrm{CO}_{2}$ is evolved by the reaction the pressure in the system increases and so does the volume of the gas phase by virtue of the fall in the near leg of the manometer. If the head in the manometer is $h$ and the cross sectional area of its bore is $a$, then the volume of gas at any time 
will be $\mathrm{V}_{0}+\mathrm{ha} / 2$. The corresponding pressure will be $p_{0}+h$. So at any time after the start of the run

$$
\left(p_{0}+h\right)\left(v_{0}+h a / 2\right)=\left(n_{a}+n_{C O}\right) R T
$$

The varjables in time are $h$ and $\mathrm{n}_{\mathrm{CO}_{2}} \cdot$ If equation (B2) is differentiated with respect to time, $\left(v_{0}+h a / 2\right) d h / d t+\left(p_{0}+h\right)(a / 2) d h / d t=\left(R^{\prime}\right) d n_{\mathrm{CO}_{2}} / d t$ or, rearranging

$$
\left(V_{0}+p_{0} a / 2+h a\right) d h / d t=(R T) d n_{C_{2}} / d t
$$

in which $p_{0}, a$, and $h$ must obviously be in units of length: $p_{0}$ must be in terms of the length of a manometric (mercury) column.

The $k^{\prime}$ to $k$ conversion involves the change from the measured velocity $\mathrm{d} h / \mathrm{dt}$ to the alternate $\mathrm{dn}_{\mathrm{CO}_{2}} / \mathrm{dt}$. So the probjem consists of evaluating the term $\mathrm{V}_{0}+\mathrm{p}_{0} \mathrm{a} / 2+\mathrm{ha}$ in equation $(\mathrm{B} 4)$.

The appropriate dimensions of the apparatus were measured and found to be: $a=28.27 \mathrm{~mm}^{2} ; \mathrm{V}_{0}=189 \mathrm{cc}=$ $189000 \mathrm{~mm}^{3}$. A typical barometric pressure for the laboratory was $745 \mathrm{~mm} \mathrm{Hg}$. If this is assumed to apply to all runs, and if the further assumption is made that an average value of $\mathrm{h}$ at midpoint in the typical run was $20 \mathrm{~mm} \mathrm{Hg}$, the pertinent factors can be calculated to be $\mathrm{v}_{0}=189000, \mathrm{p}_{\mathrm{o}} \mathrm{a} / 2=10530$, and $\mathrm{ha}=565$, all in $\mathrm{mm}^{3}$. The term ha is, therefore, only about $0.3 \%$ of the sum of the 
other two and can be ignored. The sum of $v_{0}$ and $p_{0} a / 2$ is $199530 \mathrm{~mm}^{3}$. Inclusion of this value and that of RT for $25^{\circ} \mathrm{C}$ gives

$$
\mathrm{dh} / \mathrm{dt}=92900 \mathrm{dn}_{\mathrm{CO}_{2}} / \mathrm{dt}
$$

where $t$ is in seconds, $n$ is in moles, and $h$ is in $\mathrm{mm} H$.

The other term needed for the evaluation of $k$ is the surface area, $S$, of the solid in the reaction. The crushed marble sample was sieved between the No. 16 and the No. 30 sieves. The average size of the openings of these two sieves is, from the dimensions given in ASTM $E 11$, $0.08928 \mathrm{~cm}$. If a cubical model of dimension $\mathrm{d}$ is assumed, the specific surface will be $6 / d$ in units of reciprocal length. If this value is divided by the density, $2.71 \mathrm{~g} / \mathrm{cm}^{3}$ for calcite, the specific surface in units of $\mathrm{cm}^{2} / g$ is determined to be 24.8 . A sample weight of $2.5 \mathrm{~g}$ was used in each run, so the total surface area, $S$, was $62,0 \mathrm{~cm}^{2}$. When this value is incorporated into equation (5) and combined with equations (3) and (B5), the final relationship between $\mathrm{k}^{\prime}$ and $\mathrm{k}$ becomes

$$
k=1.736 \times 10^{-7} \mathrm{k}
$$

where $k^{\prime}$ is in torr-lit/mole-sec and $k$ is in $1 \mathrm{it} / \mathrm{sec}-\mathrm{cm}^{2}$.

As an example, the apparent rate constant for the control reaction at $25^{\circ} \mathrm{C}$ is $\mathrm{k}^{\prime}=11.43$ torr-lit $/ \mathrm{mole}-\mathrm{sec}$ (Table 4); therefore the true rate constant is $\mathrm{k}=1.736 \times 10^{-7}$ $x 11.43=1.99 \times 10^{-6} \mathrm{lit} / \mathrm{sec}-\mathrm{cm}^{2}$. 
APPENDIX C 
APPENDIX C

\section{Calculation of Decrease in Acidity During a Run}

According to equation (B5) the relationship between the head developed during a run, $\Delta h$, and the moles of $\mathrm{CO}_{2}$ evolved, $\Delta \mathrm{n}_{\mathrm{CO}_{2}}$, is

$$
\Delta h=92900 \Delta n_{C_{2}}
$$

As a typical example, for the control run at $25^{\circ} \mathrm{C}$ with an initial acid concentration of $0.0354 \mathrm{H}, \Delta$ h at the end of the run was 40 torr. Therefore $\mathrm{n}_{\mathrm{CO}_{2}}=4.306 \times 10^{-4}$ moles. Twice this value, or $8.611 \times 10^{-4}$, is the number of moles of $\mathrm{BCl}$ consumed in the reaction. The original $400 \mathrm{ml}$. of acid contained $0.0364 \times 0.4=0.01456$ moles of acid. The amount consumed was, therefore, $5.9 \%$ of the original anount. The average concentration of the acid during the run was, therefore, $0.0353 \mathrm{k}$.

A similar calculation for the $25^{\circ} \mathrm{C}$ control run with an initial acid concentration of 0.0184 shows a $10.2 \%$ reduction during the run and an average concentration of $0.0175 \mathrm{~m}$. 
